\title{
Organizational Learning: A Case Study of an International Non-profit Organization
}

\author{
Olivera Andjelkovic ${ }^{1} \&$ Mehraz Boolaky ${ }^{2}$ \\ ${ }^{1}$ Business Consultant, The Hague, Netherlands \\ ${ }^{2}$ Professor of Marketing, Asia Pacific Institute of Management, New Delhi, India \\ Correspondence: Mehraz Boolaky, Honorary Lecturer and Dissertation Adviser, University of Liverpool/Laureate; \\ Professor of Marketing, Asia Pacific Institute of Management, New Delhi, India. E-mail: mehz51@yahoo.co.uk
}

Received: February 20, 2015

Accepted: March 9, 2015

Online Published: March 12, 2015

doi:10.5430/ijba.v6n2p124

URL: http://dx.doi.org/10.5430/ijba.v6n2p124

The study was carried out as part of Master in Science studies of the lead author at the University of Liverpool, United Kingdom.

\begin{abstract}
From the late 1990's onwards, the concepts and domains of organizational learning (OL) within an organizational setting and management practice have become the most debated topics among both management researchers and practitioners. At the same time, non-profit organizations endure a rapid organizational growth and re-structuring which provoke significant organizational changes in return, making the way how they learn and what they do with gained knowledge crucial for their development. However, up until now, OL remains a research area where theoretical and operational definitions fluctuate, and it is, generally, insufficiently empirically explored by both private and non-profit sectors. The role of OL in non-profits remains vague in particular, and it is yet to be fully discovered what the main barriers to OL are, or how exactly OL practices impact capacity building, performance and other important organizational areas. By using a case study approach and by focusing on working environment and operations in a single international non-profit organization, this study provides a holistic picture of OL processes by considering and integrating various important dimensions: sector to which an organization belongs, an organizational context and influence of various organizational factors. The goal is to assess the employees' awareness of the OL concept, to explore the social context and the system levels within which the learning occurs in the subject organization, and to identify the main OL challenges.
\end{abstract}

Keywords: organizational learning, non-government organization, knowledge transfer, case study, organizational factors, organizational politics and power, organizational culture, management, leadership

\section{Introduction}

At the beginning of the $21^{\text {st }}$ century, a need emerged to observe and explain ongoing organizational phenomena, such as innovation, alliances or technology implementation, and various OL concepts were there to offer new and fresh perspectives (Bapuji and Crossan, 2004). Consequently, OL has become a vital link that connects mission and economic sustainability in many organizations. Although there are many differences between researchers regarding OL definition, methodology and the role and importance of specific OL features, all of them address the issue of knowledge transfer and recognize the importance of different system levels of learning - individual, group and organizational. The large part of OL literature also agrees on the notion that a group/team is a fundamental unit where learning occurs, so, learning at team level can be considered a doorway to OL (Senge, 2006). But in general, despite the rising importance of OL, little has been done to theoretically compare and integrate the existing theoretical frameworks. Pawlowsky (2003) made an important contribution to systematization of OL theory by developing a conceptual framework of four integrative dimension of OL - learning levels, learning modes, learning types and learning processes. Nevertheless, this and other theoretical contributions to OL practice still remain insufficiently empirically explored.

In particular, the majority of organizational theories have been developed based on research in the private (for-profit) sector, and although the authors such as Drucker (1990) and Allison and Kaye (1997) offer comprehensive 
explanations of management and strategy in non-profit organizations in general, the lack of broader empirical research on this sector is still present. This applies to empirical research on OL as well. Unlike for-profit organizations, a mission of non-profits is to fill the gaps with their services that the private sector and local government have failed to address (or sometimes to also challenge the governmental role), but without providing any profits to inner or outer shareholders (member states, board members, employees, private donors, customers, legislators, etc) (Gill, 2010). Thus, rather than profit, their missions are socially and educationally driven. OL is an important concept for non-profits as the process that drives continuous organizational improvement, goal achievement and ultimately results in an organizational capacity building (Gill, 2010). Nevertheless, learning is different in different types of non-profits, therefore, in order to understand OL in any of them, it is necessary to understand their organizational context first (Senge, 2006).

The uniqueness of non-profits is further visible in the fact that there is no easy or simple way for their accountability and performance to be measured, which makes them more complex comparing to their for-profit "counterparts". There is a great donor influence usually present as well, and a significant political pressure on non-profits to deliver "desirable" results, which can (and often it does) conflict with non-profits" aspiration to learn from failures without a fear of losing credibility.

\section{Aims and Objectives}

The main aim of this study is to advance an understanding of OL in the non-profit sector by focusing on working environment and operations in a single international non-profit organization. By using a case study approach, the goal is to assess the awareness of the organizational members of the OL concept, as well as to explore the social context and the system levels within which the learning occurs in the subject organization. The study also aims to explore the impact of various organizational factors on OL processes, the role and impact of organizational politics in particular, and to identify overall OL challenges.

\section{Research Questions}

The following research questions have been formulated to guide this study:

- What is the degree of understanding of the concepts of OL in the subject organization, and how knowledge is created, shared, gathered, stored and used (on individual, group and organizational learning level)?

- How are the processes of OL (knowledge creation, transfer, capture, storage and use) influenced by the following organizational factors: organizational structure, organizational policies, leadership and management, organizational culture and organizational politics?

- What are the main impediments and barriers to OL and how could they be surpassed?

\section{Literature Review}

\subsection{Organizational Learning}

Since Cyert and March (1992) introduced the concept of OL almost half a century ago, the divergence of its perspectives is continually increasing. As expected, different perspectives have brought different definitions of OL. From the management perspective, OL is a change in people's knowledge, cognition and behavior which is closely related to other organizational changes (Argote, 2011). López, Peón and Ordás (2005, p.228) explain OL as "a dynamic process of creation, gaining and assimilation of knowledge for developing the resources/capabilities that contribute to higher organizational effectiveness and better performance". Other authors explain OL as a dynamic process of an individual that involves social, behavioral and technical dimensions and that take place within an organizational context (Crossan, Lane and White 1999; Nonaka, Toyama, and Byosiere, 2003; Rashman, Withers and Hartley, 2009). All these definitions suggest that OL goes far beyond individual knowledge and learning, and that it acts as a catalyst between learning and performance through numerous structural variables. Specifically, the role of $\mathrm{OL}$ is to ensure that individual knowledge and learning ultimately leads to organizational knowledge and learning.

There are numerous OL perspectives and their different theoretical basis, namely, system-theory, cultural, cognitive/knowledge or action-learning point of view. The differences that exist are manly related to the terminology that is still not quite aligned and to epistemological/ontological differences. The Theory of Organizational Knowledge Creation, one of the most known OL theories, was conceptualized two decades ago by Nonaka and his colleagues. It was an attempt to clarify the vague theoretical ground of OL processes and explain how organizational knowledge is created and shared. Von Krogh, Ishijo and Nonaka (2000, p.22) describe knowledge as "a justification of one's beliefs" and knowledge sharing as public justification of one's beliefs. Consequently, as knowledge is 
highly dependent on people's ideas and values, the nature of knowledge is described as tacit (unarticulated) and explicit (formulated and captured) (Nonaka and Van Krogh, 2009, p.636).

The authors introduced the knowledge spiral where knowledge is created in the mutual interaction of 3 important layers: knowledge creation and conversion mechanisms (SECI model), context (called as " $\mathrm{Ba}$ ") and knowledge assets. The SECI model, as the first layer, shows how tacit and explicit knowledge interact and convert through social processes (socialization, externalization, combination and internalization) between individuals and describes the dynamic nature of knowledge (mobility across organizational levels and externally). Originating $B a$ - contexts, platforms for knowledge creation (social, cultural, historical, physical, mental or virtual) and knowledge assets (specific resources essential for the value/knowledge creation) are the other two layers necessary for forming the knowledge spiral which ultimately creates knowledge (Nonaka, Toyama and Byosiere, 2003, p.493). The authors highlight the role of knowledge activists (leaders, managers) as knowledge creation catalysts and coordinators. They underline care, knowledge vision, communication, the right context and common language as vital enablers of knowledge creation. Furthermore, they also stress the importance of organizational processes and organizational structure through the concepts of the middle-up-down management, the hypertext organization and distributed leadership (Von Krogh, Nonaka and Rechsteiner, 2012).

Another important theoretical approach was offered by Crossan, Lane and White (1999) as the 4I Framework - a dynamic model of OL that includes 4 stages of knowledge conversion: intuiting (a development of new insights based on experience), interpreting (explaining new insights), integrating (shared understanding on group level) and institutionalizing (implementation of shared understanding on organizational level). Crossan's model also includes two types of knowledge - tacit and explicit, and tree knowledge levels - individual, group and organizational. This model explains OL as a multidimensional and dynamic process where learning occurs on different levels over time and it creates "a tension" between assimilation of new and exploitation of existing knowledge (Crossan, Lane and White, 1999, p.532).

Senge (2006) also contributed to the OL theory with the Concept of Systems Thinking. From the management perspective, Senge's system thinking is an ability to discover structural causes of behavior and it is necessary for sustaining generative learning which is a foundation for people's creativity and an essence of OL. Furthermore, together with other 4 disciplines for building the learning organization - personal mastery, mental models, shared vision and team learning, systems thinking enables organizations to recognize long-term patterns of change (Senge, 2006, p.190). Accordingly, Senge advocates a shift of leadership from the traditional concept as well, suggesting that "leaders must become teachers, designers and stewards" (2006, p. 321).

Pawlowsky (2003) tried to bring different OL perspectives closer to management through the integrative framework that shows all main dimensions of OL: system levels, learning modes, learning types and phases of the learning process. He stressed the importance of values, emotions and behavior in learning (cultural learning mode) and pointed out trust in organizational members and in management as the factor of the organizational culture that must not be ignored.

However, even though the theoretical frameworks of OL described above significantly contribute to an understanding of learning within organizations, they all show some weaknesses. While both Nonaka's and Crossan's frameworks systematically address OL, they fail to include other important dimensions that are closely related to people's behavior, such as political and cultural. These models also disregard people's values, ethics, motivation, affective reactions, and generally, people's emotions and feelings as important aspects of knowledge and learning. Senge's holistic organizational approach also gives the realistic perspective of knowledge dissemination throughout an organization and it helps to understand the role of different organizational factors. Yet, it describes OL rather as an organizational state that waits to be achieved, than a continuous process.

\subsection{Organizational Learning and Organizational Factors}

Although it is still not fully clear what organizational factors affect the development of OL and in which way, recent studies on OL show that organizational type/structure, strategy, leadership and organizational culture influence individual, team, organizational and (in the case of non-profits) community learning as well - either as enablers or impediments.

So far, organizational structure is the most frequently addressed factor in empirical studies on OL. The findings in some studies (Ashton, 2004; Martínez-León and Martínez-García, 2011; Rebelo and Gomes, 2011) indicate that OL development involves flatter organizational structures with open communication channels and circulation of information and that relies on management that practices the right balance of control and authority. As the part of the 
organizational infrastructure, the role of IT systems in the processes of OL is also very important, particularly when it comes to the transfer of explicit knowledge (Alavi and Leidner, 2001).

When it comes to organizational policies, Suppiah and Sandhu (2011) discovered that certain human resource (HR) policies, such as recognition and rewarding, are particularly influential managerial instrument for encouraging the sharing of tacit knowledge. López, Peón and Ordás (2006) also found a positive correlation between OL and the HR practices of training and selective hiring. Similarly, Droege and Hoobler (2003) discuss that employment policies that cause relatively high employee turnover, like temporary employment or limited tenure, could ultimately result in losing knowledge, expertise and experience of the members who leave the organization. Zell (2001) suggests that this could cause a disruption and discontinuity of organizational memory, which ultimately affects and hinders knowledge storing and implementation of innovation (new practices and ideas).

Contrary to traditional, autocratic command-and-control leadership, in learning organizations leaders/managers are described as teachers, coaches, stewards and designers (Senge, 2006). More precisely, current OL literature suggests that, in order to develop a fertile ground for OL, leaders/managers should provide the right amount of employee autonomy, a high level of mutual trust (high-care environment) and employee empowerment. Likewise, Von Krogh, Ishijo and Nonaka (2000) refer to mutual trust in organizations as the primary dimension of organizational care. The studies of Liao (2006) and Holste and Fields (2010) confirmed the crucial role of trust in OL processes by finding that trust strongly positively influences knowledge sharing. The studies of Wielenga-Meijer et al. (2011) and Li et al. (2010) found that a successful balance between full managerial autonomy and full managerial control positively affects the processes of knowledge creation and sharing. These results suggest that finding such balance might depend on the leadership style applied. Von Krogh, Nonaka and Rechsteiner (2012) pointed out that leadership in the OL theory is viewed either as activity/process/position centrally controlled (centralized leadership), or as a distributed activity between individuals, team members or departments (distributed leadership). The authors argue that, in reality, however, leadership styles usually oscillate between these two styles and their complementary roles is playing a fundamental part of the successful knowledge creation process (Von Krogh, Nonaka and Rechsteiner, 2012, p.269).

According to Nonaka, Toyama and Byosiere's beliefs (2003), organizational culture (as one of the $B a$ contexts) enables tacit and explicit knowledge to be created and shared without restraint. Communication and collaboration are probably the most important dimensions of organizational culture which promote knowledge creation and sharing (Janz and Prasarnphanich, 2003). In their empirical study, López, Peón and Ordás (2004) found that collaborative organizational culture promotes OL. Suppiah and Sandhu (2011) came to similar conclusions - clan (team, collaborative) and adhocracy (empowered, risk-oriented) organizational cultures strongly promote sharing of tacit knowledge, while bureaucratic (high-hierarchy) and competitive (market) organizational cultures influence negatively. Naturally, organizational cultures are usually a mixture of two (or more) types that are described above, so positive or negative influence on OL processes would be determined by the cultural type that dominates.

Organizational politics are usually referred to as self-serving, self-interested behavior of individuals who want to achieve benefits and advantages at the expense of others and it is inseparably linked to power (Vigoda, 2000). The existing body of literature mainly focuses on OL through psychological and social processes, while organizational politics and power remain rarely theoretically and empirically addressed, particularly in the non-profit sector. Organizational politics and power within OL context do not necessarily have to carry a negative connotation (Roome and Wijen, 2006; Blackler and McDonald, 2000). Townley (1993) suggests that, besides individual (episodic) power, the systemic form of power affects perception, imagination and behavior of individuals, which ultimately affects the OL process. Lawrence et al. (2005) also argue that organizations are primarily political systems where predominantly self-interested actors operate, and where different forms of power and political strategies determine whether and how successful OL cycle will be. The authors used the Crossan's 4I model of OL to explain the political dynamics of OL. In their framework, they suggest that every learning process is connected to a specific form of episodic or systemic power - intuiting to discipline, interpreting to influence, integrating to force and internationalizing to domination, and if properly balanced, these forms of power enhance OL. The way organizational members perceive the level of organizational politics at their workplace is crucial. According to some authors, the higher the perceptions of politics are, the lower will be the perceptions of equality and fairness, which ultimately leads to the low level of openness and trust, thus, to reluctance towards knowledge sharing (Ferris and Kacmar, 1992; Vigoda, 2000).

\subsection{Barriers to Organizational Learning}

In recent years, an increasing amount of literature addresses various factors that impede OL. As mentioned earlier, Lawrence et al. (2005) consider organization politics and power as potential and serious obstacles to OL. Schilling 
and Kluge (2009) went further; they expanded the Crossan's 4I framework and systematically categorized barriers to OL. The authors identified three types of barriers: actional-personal, structural-organizational and societal-environmental, and explained their complex and interconnected influence on the individual, group and organizational learning through 4I processes (intuiting, interpreting, integrating and institutionalizing).

\subsection{Research Gap and Unaddressed Issues}

Although there is a growing body of literature on OL, it is mainly connected to for-profit sector. There is little evidence of how learning occurs in non-profit organizations, are they aware of the OL concept and to what extent and what the main obstacles to learning are. Moreover, the research on factors that have influence on OL is mainly theoretically based and still in the conceptual domain of propositions, so, many of OL concepts are yet to be empirically tested. For instance, while the impact of organizational structure, policies and leadership on OL is widely acknowledged and studied for some time now, the influence of organizational culture has just recently started to attract the closer "empirical" attention of researchers through the concept of learning culture. Also, the existing body of OL literature poorly addresses power and politics and their influence on OL processes and these factors are almost completely ignored when it comes to non-profit sector. The importance of the role of organizational politics in knowledge and learning is even more pronounced when non-profits have a large number of stakeholders and when their mission/work is of a global importance.

\subsection{Theoretical Framework}

A review of Nonaka, Toyama and Byosiere's (2003) and Crossan's (1999) frameworks of OL and other important empirical studies listed above yielded some important concepts for this research and enabled the theoretical framework to be developed. In this study, relations between the processes of knowledge sharing, capture, storage and use, organizational context and organizational factors, are explored through the aspects and variables as shown in the theoretical framework developed by the authors (Figure 1).

Individual, Group/Team and Organizational Learning

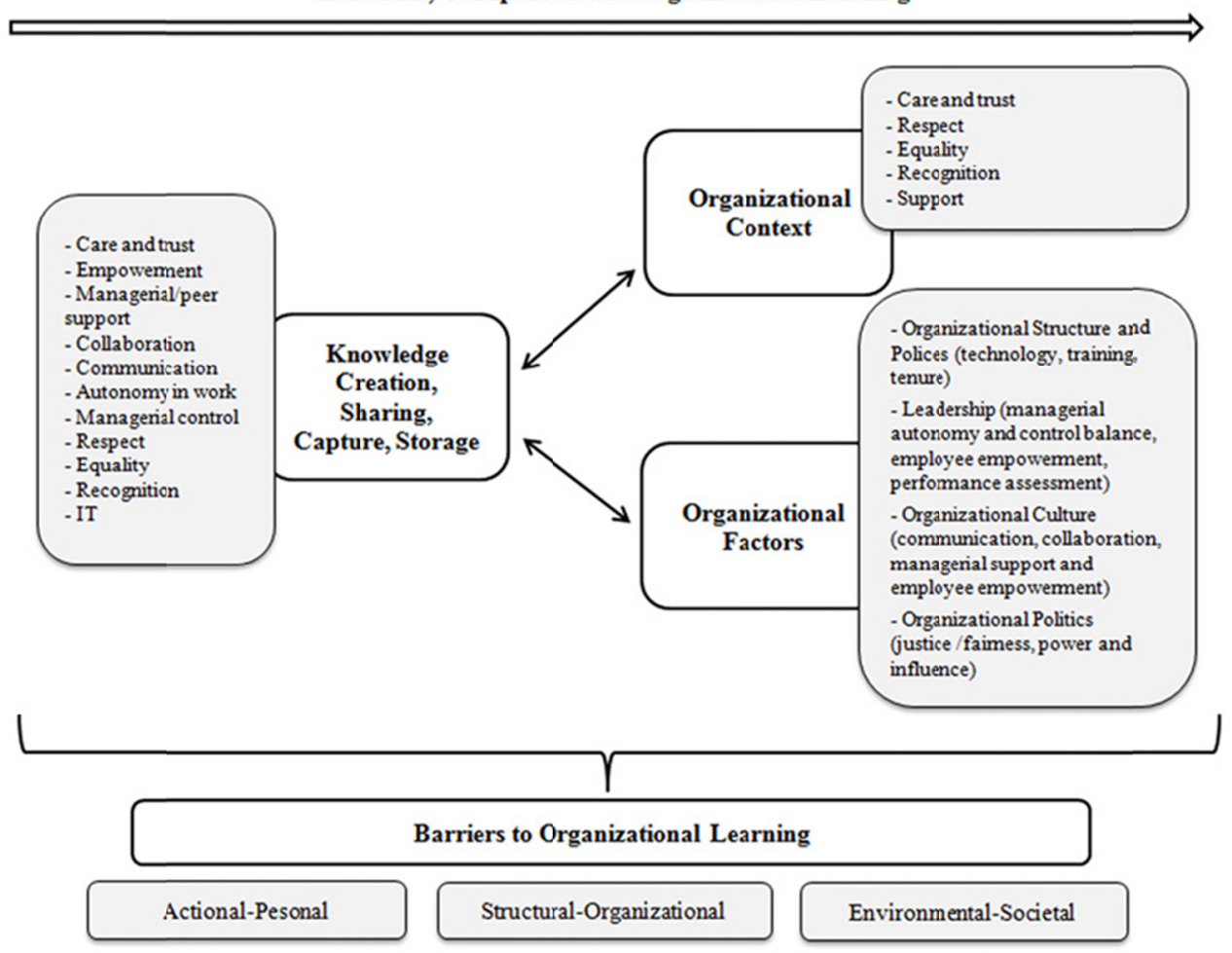

Figure 1. Theoretical framework for studying OL processes and barriers in NGOX

The theoretical concepts and research studies presented earlier are crucial for understanding, framing and addressing the research questions in several ways. First, the Theory of Knowledge Creation and the 4I model offer the basis for understanding of how OL in NGOX (the name of the organization is changed to keep it confidential) occurs at individual, group and organizational level, thus, enable the first research question to be answered. In order to answer the second research question, the research of Martínez-León and Martínez-García (2011) and Droege and Hoobler 
(2003) are used as a guideline for exploring the influence of organizational structure and organizational policies on knowledge creation, sharing, storing and use. Technology and the processes of communication are used to identify what the dominant type of organizational structure is and whether the current training and tenure policies act as OL enablers or not. And finally, Crossan's (1999) 4I framework and the upgraded version provided by Schilling and Kluge (2009) are used to determine and systematize the types of learning barriers in NGOX, thus, to answer the third research question.

\section{Research Design and Methodology}

The overall research strategy is based on a single case study of an international non-profit organization. The authors chose NGOX because its operations highly rely on knowledge and learning and it is large enough to provide rich and sustainable research data. The case study approach is based on the method of triangulation in order to provide a greater validity to research results (Molina-Azorin, 2010), as well as to collect enough relevant data and link them with theory through the theoretical framework. Quantitative and qualitative research methods were combined and both questionnaire and interview techniques were applied throughout two large research phases.

In the quantitative phase, the target population included all 350 employees at NGOX, and 149 participants were selected by using the random (probability) sampling technique. The SurveyGizmo software was used and the online questionnaire was created and made available to the participants during the period of 4 weeks on the SurveyGizmo website (SurveyGizmo, 2012). All the participants were anonymous. The SurveyGizmo software was also used for gathering, analyzing and presenting the research data.

In creating the questionnaire, various closed-ended question types were used: mutually exclusive multiple choices, checkbox questions and the Likert scale questions (Brace, 2008). The questionnaire was based on the typology of questions presented in the Dimensions of the Learning Organization Questionnaire (DLOQ) (Marsick and Watkins, 2003). The final questionnaire included 30 closed-end questions and it was divided into 4 sections: the concepts and levels of organizational learning, organizational structure and policies, learning barriers and general information.

The qualitative phase of data collection included the use of interviews, with a non-probability, purposive sampling technique (maximum variation sampling) (White, 2000). The representative sample was selected from 3 different organizational levels - management, administration and field operations. It included 6 staff members -2 managers, 2 administrative/technical officers and 2 field experts. The aim is to explore the differences in perceptions on OL between members at different organizational levels. A semi-structured type of interview and an individual interview technique with open-ended questions were used (Fontana and Frey, 2003). The final interview protocol included topics and questions related to: employee perception of the organization and its context; knowledge creation, transfer, capture and use; organizational structure and policies; management and leadership; organizational culture; organizational politics and power and learning barriers. The participants were encouraged to discuss them in an open manner.

\section{Analysis and Results}

Data collection lasted eight weeks. As for the first phase, 62 respondents had started answering the questionnaire, 57 of them fully completed it, of which one third are female. 5 partial questionnaire responses are disqualified, so the total questionnaire response rate is $38.2 \%$. In the second phase, 6 interviews were conducted: 2 with managers, 2 with field officers and 2 with administrative employees. It is worth noting that on the education front, most of the persons interviewed possessed a good level of education and only $8.8 \%$ of respondents studied up to the secondary level (Figure 2 refers).

What is the highest level of education you have completed?

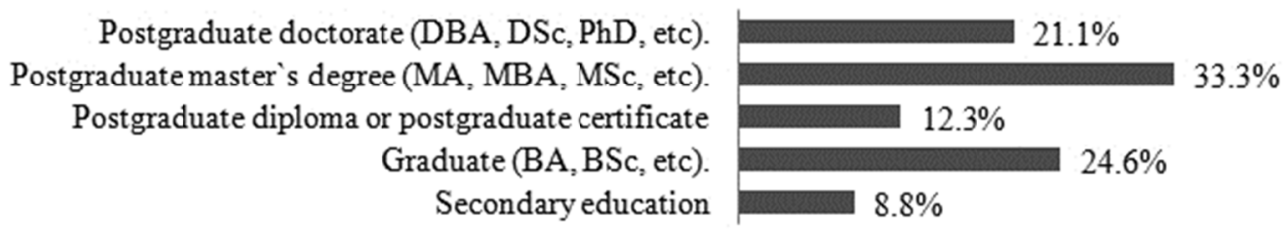

Figure 2. Education level

\subsection{Understanding of the Concept of Organizational Learning and the Way Organizational Processes Occur}

According to the research results, NGOX's employees are highly aware of the concepts of OL, which is very encouraging and implies that employees are mostly willing to further learn, share knowledge, and advance 
professionally in general. Such strong commitment to learning might also be a result of respondents' high levels of education (Figure 2). However, although NGOX emphasizes training and officially offers new learning opportunities equally to all, motivation to learn is most likely individually driven, particularly within the technical experts who tend to be always up to date with the latest technical developments in their fields, in order to stay competitive as employees. Also, the role of team leaders and branch/divisional managers who act as mentors, plays an important part in employees' professional advancement, but yet, this is still an exception rather than a rule.

Table 1. The employees' perception of the organizational structure

Total Responses/Participants:

\section{Responses}

Number of
participants $\quad$ Percent

Highly hierarchical (many vertical levels with the authority figure on top), bureaucratic and formalized (focuses on positions and roles and has fixed set of rules).

29

27

show flexibility in their work and express their opinions freely.

Decentralized (decision-making authority is delegated down to the lower organizational levels), with proactive employee participation and important role of team/group work.

N/A.

Total Responses/Participants:

From Table 1, it is noted that $47.4 \%$ of respondents confirmed that although the structure of the organization is hierarchical, there are considerable levels of care, trust, respect, equality, recognition and support among organizational members within groups at NGOX enabling flexibility, participation and opportunities to express opinions freely. Since these variables, and particularly trust and care, have positive influence on knowledge creation and sharing (Von Krogh, Ishijo and Nonaka, 2000; Liao, 2006; Holste and Fields, 2010), these aspects of organizational context in NGOX (i.e. originating, dialoguing and exercising $B a$ ) make a fertile ground for knowledge creation and conversion. Since NGOX possesses and uses various forms of advanced information technology (systemizing $B a$ ), that also makes a good basis for efficient explicit knowledge creation and transmission (Nonaka, Toyama and Byosiere, 2003). Nonetheless, the majority of the interviewees (50.9\% as noted in Table 1) think that, contrary to the atmosphere in groups/branches, the atmosphere between divisions is rigid, official and competitive. Such situation suggests that, although there is a reasonable chance for OL to become institutionalized due to high levels of trust, care, respect and assistance in a group/team work, the links are probably broken at the organizational level where various organizational schemes (reflected in routines/systems) fail to develop, also failing to make an impact on group and individual learning in return (Crossan, Lane and White, 1999).

Generally speaking, the research results offer a relatively clear answer to the part of the first research question related to the processes of knowledge creation, transfer, capture, storage and assimilation at NGOX. These processes occur partially since all of them face various obstructions and difficulties at different levels. The conversion from tacit to tacit knowledge (socialization) is somewhat enabled, firstly, because the willingness, competence and capability to learn exist, and secondly, because the organizational context within a group (originating $B a$ ) is nurturing (Nonaka, Toyama and Byosiere, 2003). Conversely, there is no sufficient individual autonomy in work, which has a negative impact on employee creativity and innovation, thus, negatively affects the processes of tacit knowledge creation and utilization, as the study of Prugsamatz (2010) also revealed. Moreover, due to strong bureaucracy and politics, innovative ideas are either very slowly or not accepted at all, which is a serious impediment to knowledge creation and use.

Interview findings confirm that people at NGOX are generally interested in learning and the actual opportunities for that are officially given to them, which means that good foundation for knowledge conversion from explicit to tacit (internalization) should exist. But in reality, learning opportunities are often either financially limited or have been manipulated by managers. So, some employees, although willing to learn, often end up pushed aside from some objective or subjective reasons. These findings are typical for hierarchical and bureaucratic organizations and they are in accordance with Ashton's study (2004) which revealed that in such organizations, although officially everybody has a fair chance for professional advancement, in practice the chance is mostly given to the people with 
more influence or on higher positions. So, ultimately, the process of internalization of knowledge in NGOX is affected by this, and in many cases, at least partially disabled.

Table 2. Work place perception

\begin{tabular}{lcc}
\hline I would describe my organization as: & & \\
\hline Responses & $\begin{array}{c}\text { Number of } \\
\text { participants }\end{array}$ & Percent \\
\hline $\begin{array}{l}\text { Friendly place with developed teamwork and employee commitment to organization and } \\
\text { vice versa. }\end{array}$ & 17 & $29.8 \%$ \\
Creative workplace with empowered and risk-taking employees. & 3 & $5.3 \%$ \\
Competitive workplace where knowledge is power. & 6 & $10.5 \%$ \\
Workplace with standardized procedures, practices and rules with little (or none) & 30 & $52.6 \%$ \\
collaboration between divisions/units. & 1 & $1.8 \%$ \\
N/A. & $\mathbf{5 7}$ \\
\hline Total Responses/Participants: & \\
\hline
\end{tabular}

Questionnaire results suggest that the process of externalization (tacit to explicit) is mainly enabled, since 29.8 percent of respondents do not significantly refrain to share new ideas with others and training programs (learning-by-doing) are highly valued at NGOX (Table 2 refers). However, interviews further show that this is the case manly with the people on the same team or working group (branch, division). Even there, a good majority of employees $(52.6 \%)$ as shown in Table 2, subjects to the tenure policy, believe that there is little collaboration between units and divisions implying that they prefer to withhold their knowledge or new ideas. So, the process of externalization in NGOX does face some difficulties when it comes to people's willingness to share knowledge and ideas. This leaves negative consequences on tacit-explicit knowledge conversion, particularly among the people with the very specific or high expertise.

The knowledge conversion from explicit to explicit (combination) faces some obstacles too. The main problems identified are, again, insufficient communication and collaboration between divisions, high employee turnover and inconsistent implementation of tenure policy. Also, although appropriate modern technologies that should be facilitating this type of knowledge conversion exist, they are not user-friendly. Ultimately, explicit knowledge in NGOX is not combined, collected or disseminated properly, so it is questionable how much such knowledge is really usable for organizational members. It is pretty discouraging that, despite all NGOX's technological potential, there are still no appropriate (or efficient) mechanisms established for collecting, combining, upgrading and storing knowledge or making such knowledge widely available.

\subsection{Organizational Structure and Organizational Learning}

Communication channels and information flow in NGOX are mostly open within a team, branch or a division, but not between divisions. A high level of bureaucracy makes communication at the organizational level official, formal and restrained, consequently making knowledge creation, transfer, capture, storage and use more difficult to occur (Table 3).

Table 3. The impediments to knowledge storing and implementation

In my opinion, new knowledge storing and implementation in my organization is mainly hindered by:

\begin{tabular}{lcc}
\hline Responses & $\begin{array}{c}\text { Number of } \\
\text { participants }\end{array}$ & Percent \\
\hline $\begin{array}{l}\text { The lack of skills both of employees and management or their opportunistic } \\
\text { behavior. }\end{array}$ & 9 & $15.8 \%$ \\
$\begin{array}{l}\text { High employee/management turnover or inconsistent organizational systems, } \\
\text { practices and policies. }\end{array}$ & 28 & $49.1 \%$ \\
$\begin{array}{l}\text { General problems (technical/structural) in storing certain kinds of } \\
\text { knowledge. }\end{array}$ & 18 & $31.6 \%$ \\
N/A. & 2 & $3.5 \%$ \\
\hline Total Responses/Participants: & $\mathbf{5 7}$ & \\
\hline
\end{tabular}


For instance, the knowledge creation suffers because of the slow bureaucratic procedures where many new ideas or solutions remain unknown, or they become acknowledged but not approved and implemented at the end. The OL processes are generally hindered by too many rules about interdivisional communication and by many restrictions (visible or invisible) in accessing the information from different organizational levels.

Moreover, IT potential to act as OL enabler is mostly lost, because it constantly faces barriers imposed by the high hierarchy and bureaucracy. Such findings are actually in accordance with the empirical studies of Martínez-León and Martínez-García (2011) and Rebelo and Gomes (2011) that found that with the flatter organizational structure the OL processes become more open and vice versa.

\subsection{Organizational Policies and Organizational Learning}

Tenure and training policies are strongly mutually connected and influenced by other organizational factors, particularly by organizational politics and management, which, in turn, affect the levels of motivation, trust and respect, and the perception of fairness and justice within the organization.

The research results suggest that the 7-year tenure policy mostly negatively affects OL processes in NGOX. Firstly, because the implementation of this policy is politicized and it directly hinders knowledge creation and transfer, and secondly, because the OL processes are generally disturbed since the outflow of knowledgeable people is often accompanied by the inappropriate or insufficient mechanisms for gathering, storing and dissemination of their knowledge and expertise. Similarly, although training polices are well designed, their implementation is very often politicized. This inconsistency in applying the organizational policies creates an atmosphere where employees start to see organizational processes as unfair and the use of power and influence as the only way to go ahead. The processes of recruitment and promotion face similar problems, so generally speaking, it appears that implementation of the HR policies in NGOX is mainly politicized and under various individual influences.

Such results support the previous research and findings of Zell (2001) and Droege and Hoobler (2003) - the employment policies that cause relatively high employee turnover (i.e. temporary employment, tenure) result in losing knowledge, expertise and experience of the members who leave the organization and cause disruption and discontinuity of organizational memory. Therefore, although the policies in NGOX are essentially well designed, their inconsistent and selective implementation leads to obstructions in the organizational processes where knowledge is created, shared, further combined and used. This also accords with the earlier observations of Schilling and Kluge (2009) that inconsistent organizational polices are the most common barriers to OL at organizational level.

\subsection{Leadership/Management and Organizational Learning}

While the questionnaire findings illustrate management as the creator of trusting and caring working atmosphere and the promoter of learning (which is mostly the perception of male employees), the interview results show that, in practice, this is true mostly when it comes to team leaders and middle managers. Top management is nominally dedicated to the advancement of knowledge and learning, but there is no real action to underpin such determination. Some of the middle managers and team leaders, however, do act as tutors and coaches and show the right balance of managerial autonomy and control, empower employees and create the atmosphere of trust, respect and collaboration within their unit/branch/division. By doing that, they promote OL processes and act as knowledge activists and catalysts, as their role should be, according to Von Krogh, Ishijo and Nonaka (2000). However, this is not the case within all the teams and branches, and as the interview findings confirmed, management in NGOX is still more about command-and-control.

Given this and the fact that the actual strategy or support to knowledge and learning from top management is missing, it can be concluded that leadership/management at NGOX generally does not act as enabler of OL. Obscure communication between organizational levels and in the huge political influence of external stakeholders on top management decisions and actions do not make the situation any easier. Moreover, NGOX's high hierarchy and bureaucracy do not allow managers to act much beyond the limitations that such organizational structure impose; i.e. it will be hard for NGOX's managers to move from centralized to distributed management style, unless the organizational structure becomes more flatter, as Von Krogh, Nonaka and Rechsteiner (2012) also concluded.

\subsection{Organizational Culture and Organizational Learning}

There is a mixture of three types of organizational culture present at NGOX: clan (team, collaborative), bureaucratic (high-hierarchy) and competitive organizational culture (Suppiah and Sandhu, 2011). These types of culture are, conversely, the most contradictory ones when it comes to their impact on OL. While clan culture enhances OL, bureaucratic and competitive impede it. Also, clan culture in NGOX is more typical for teams, branches and, in rare cases, divisions, while hierarchy and competitive cultures dominate the relations between divisions and at 
organizational level in general (Table 2). Given this, it is most likely that organizational culture in NGOX affects OL more negatively than positively.

\subsection{Organizational Politics and Organizational Learning}

Power games and individual influences significantly determine work processes and relations between people in NGOX (Figure 3).

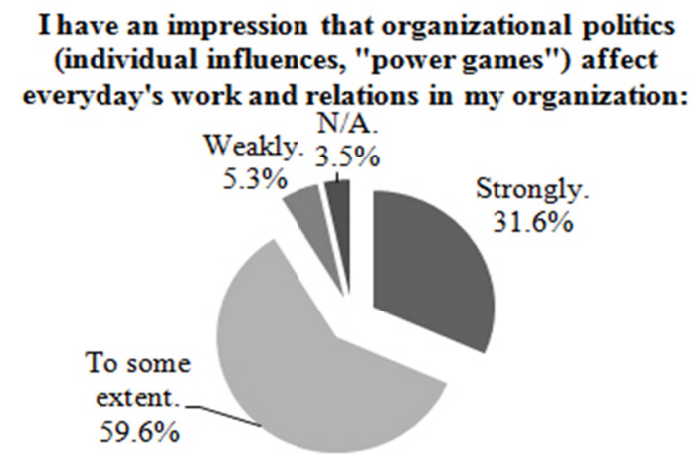

Figure 3. Organizational politics and work relations

Fairness and justice are present mostly within the groups or branches. What is surprising is that, despite such findings, the majority of respondents claim they do not withhold their knowledge because they perceive the atmosphere at their workplaces as unfair (Figure 4).

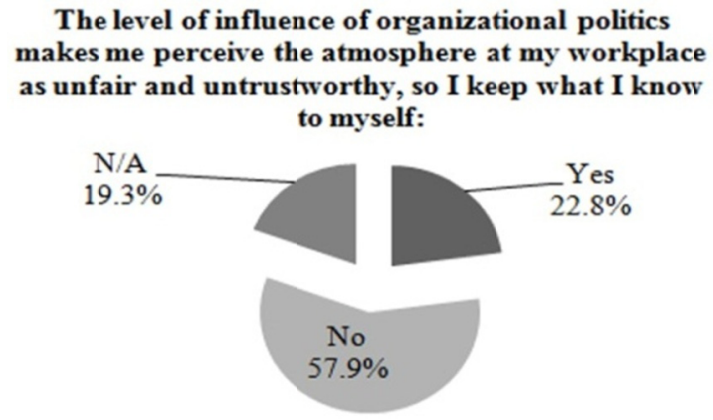

Figure 4. Organizational politics and workplace atmosphere

Such results differ from earlier findings of Vigoda (2000) and Ferris and Kacmar (1992) that revealed how high perceptions of organizational politics make employees perceive their workplace as unjust and untrustworthy and have negative influence on their knowledge sharing behavior. However, the results are in accordance with some later studies (Lawrence et al., 2005; Roome and Wijen, 2006) that perceive organizations as predominately political systems, and that suggest that connections between learning processes and different types of power should not be perceived as negative by default. Therefore, in the case of NGOX, the role of individual influences in the processes of sharing knowledge and new ideas do not have to necessarily be an impediment to OL. For instance, for new solutions/ideas to be acknowledged, accepted or disseminated in NGOX, it is necessary to rely on and use various individual influences on different organizational levels. So, from that perspective, influence, as a form of power/politics, could actually enhance the processes of OL by enabling knowledge transfer and knowledge assimilation to actually occur.

However, judging from the interviews, organizational politics with their direct or indirect influence on other organizational factors, hence on OL, do not generally create a fair "playground" for the majority of organizational members in NGOX. Instead, politics distort and dictate actions and events, having largely unfavorable influence on organizational processes.

\subsection{The Main Barriers to Organizational Learning in NGOX}

The results of the NGOX's case study answered the third research question and revealed that learning difficulties and blockages in the processes of OL are, more or less, present at every organizational level. At the individual learning level where knowledge creation occurs, the only set of barriers that exists is structural-organizational: the low level 
of freedom in general, either due to the centralized, command-and-control management approach or due to strict working rules and procedures as revealed in Table 3.

The processes of knowledge transfer and sharing from an individual to a group level are mostly hindered by the employees' perception of interpersonal relationships (actional-personal barrier). If they refrain to share knowledge, this is because of the low trust and respect or weak individual influence - ultimately the result of insufficient managerial support and the influence of ubiquitous organizational politics (Table 3 refers). This can be also seen by looking through the organizational-structural prism in the interrelations determined by the organizational culture that values power, status and influence, and in highly hierarchical organizational structure. Environmental-societal barriers to knowledge transfer and sharing are mainly comprised in existing differences between divisions conflicting objectives or values and hidden agendas as well.

At the organizational learning level, the largest number of barriers is present in the processes of knowledge transfer, capture, storing and use. Factors such as lack of true commitment and support to learning from top management, low communication and collaboration between divisions, and strong bureaucracy and political influence have created a situation where some teams, branches, and in rare cases divisions in NGOX do learn, while the whole organization does not, because that knowledge is not properly addressed and integrated into organizational practices. Moreover, there is the predominant belief in NGOX that innovative ideas and solutions are not welcome, because the existing mindsets are mainly reluctant to change.

Structural-organizational barriers to knowledge capture, storing, dissemination and use are identified as inconsistent implementation of tenure and training policies, high turnover of field experts, lack of clear strategy and responsibility for knowledge storage and implementation and general technical difficulties in knowledge storage and dissemination (Table 3). All these barriers make knowledge integration ultimately dependent on individual influences and power, as Lawrence et al. (2005) suggest. As a result, there is no sustainability in the OL processes whatsoever, and it is hard to say whether and how such barriers can be successfully surpassed. However, some recommendations are further given.

\section{Conclusions and Recommendations}

\subsection{Summary of Conclusions}

- General conclusion about the first research question is that knowledge creation, sharing, capture, storage and use in NGOX occur partially and discontinuously, and despite the fact that employees are highly committed to learning and fully understand the concept of OL, NGOX do not nurture or exploit such potential further, so learning is trapped somewhere between individual and group level.

- In relation to the second research question, it can be concluded that organizational structure, organizational policies (tenure, training), leadership and management, organizational culture and organizational politics in NGOX affect the processes of OL more negatively than positively due to complex linkages between them. Moreover, organizational politics, i.e. individual and particularly stakeholders' influence and power games, have a dominant influence on all other organizational factors.

- The conclusion about the third research question is that structural-organizational barriers are the most frequent barriers to OL in NGOX and present at all learning levels. Thus, in order to facilitate OL processes in NGOX, significant changes in organizational structure, policies, procedures and practices are needed. Interestingly enough, among all OL processes, knowledge creation appears to face the lowest number of obstructions and all of them are structural-organizational. Adding the fact that team leaders are identified as the ones that most frequently act as mentors and learning activists, the conclusion is that learning occurs mostly at individual and team level.

- Another conclusion emerged from this study is that NGOX, as an international non-profit organization, has similar issues when it comes to OL as the for-profits described in studied literature. However, what makes non-profits such as NGOX specific when it comes to learning is the role of stakeholders. Specificity and a global importance of NGOX's operations inevitably comprise the large number of member states with various interests, political agendas and political games. Consequently, power and influence of stakeholders simply cannot be avoided, which puts a challenge and constraint on organizational processes in general, including OL.

\subsection{Recommendations to Management}

- In order to achieve learning at organizational level, NGOX must be fully devoted to develop a learning-friendly environment that will turn learning orientation and commitment of individuals into group and organizational commitment and goal. This can be achieved, for instance, by forming cross-functional teams from members of different divisions to fulfill some of the organizational goals. In that way, knowledge creation and diffusion among members would be enabled, and this might ultimately decrease some divisional 
gaps and improve collaboration at organizational level. Moreover, work in cross-functional teams will make authority and responsibility more dispersed across organizational levels, which is, again, beneficial for learning.

- Managers at every level, and particularly and especially divisional managers and the Director General, must provide contextual and resource-based support for learning, while they simultaneously change the command-and-control approach into approach that makes them become learning activists and facilitators. It means that, while guiding, they should enhance work related autonomy as precondition for innovation and creativeness, and communication across organizational levels as a prerequisite for knowledge integration and diffusion.

- Organizational factors should be put in service of OL. NGOX should adopt organizational structure that is more flat and decentralized in order to mitigate or remove the existing structural barriers to learning. E-learning should be seriously considered for all training where possible - it will not only give more flexibility in learning to temporary dispersed employees (on field), but also significantly cut the training costs in the long run. Furthermore, roles and responsibilities about who is accountable for knowledge capture, storage and assimilation should be clearly defined, and all related processes as well. Consequently, the functioning of technology platforms (databases, networks) will be less complicated and more user-friendly.

- However, some issues related to OL in NGOX will still be hard or even impossible to resolve. Power and politics are, for instance, obviously "here to stay" because the very nature and purpose of NGOX imply that stakeholders will keeps to politically interfere in organizational activities and influence them through the upper management. Power games and individual influence, however, might be mitigated by improving communication and collaboration between organizational levels through the creation of cross-functional teams and by providing transparency in managerial actions and decisions and in organizational processes and practices in general. The negative impact of organizational politics could be also mitigated if managers succeed to align individual needs and goals with those of the organization.

- Proper implementation of incentives that recognize and reward learning-related behavior should be enabled by giving transparency in procedures and practices that result in one's promotion, public recognition, training approval or other types of incentives. When people start to perceive such processes as just and fair, the overall organizational climate will start to change and it will become more collaborative, caring and empowering. As a result, NGOX's organizational culture will probably lose its competitive side.

- Implementation of tenure policy will probably remain an issue, up until those who are responsible for deciding who will stay and who will go become fully aware that they are also responsible and accountable for continuity in the processes of knowledge creation, transfer, capture, storing and dissemination.

- Finally, since a single learning barrier could simultaneously influence different levels and different processes of learning, in order to make efficient strategies for surpassing learning barriers, managers have to consider all the barriers as a complex system, rather than analyze them and resolve them as separate factors.

\subsection{Limitations and Recommendations for Future Research}

This study contributes to the body of knowledge by filling the existing gap in research on OL processes and practices in the non-profit sector. The study value primarily lies in the fact that it clarifies and explains in more depth the OL processes and the role of NGOX's organizational factors in the processes of OL, the role of organizational politics in particular.

First limitation to this study would be the number of conducted interviews. A larger number of interviewees would give more width to research and more possibility for some new, unaddressed themes to appear. Second, the study research was designed and conducted to answer the questions about OL in a single and specific non-profit organization that operates globally and for the public interest. As such, the research results cannot be generalized to other non-profits. However, the method of triangulation was deployed so cross-confirmation from different data sources (questionnaire end interview) ensures the validity of research. For more comparative treatment and if time had permitted, the author would have considered a multiple case study approach with at least two different types of non-profits.

There are several suggestions for further research. From the single case study perspective, further closer research on stakeholders' political influence in NGOX would be a valuable source of information related to OL and other organizational processes, policies and practices. Also, the influence of other organizational factors that were not included in this study should be examined in order to better understand learning constraints and enablers in NGOX for instance, the influence of limited resources or of organizational mission, vision and strategy on OL. Furthermore, for providing the answers about OL that could be applied in the non-profit sector in general, further correlational quantitative research on a large number of different non-profits is needed in order to explore and determine exact 
correlations among organizational politics, organizational structure, organizational policies, organizational culture and leadership, and their influence on OL.

\section{References}

Alavi, M., \& Leidner, D.E. (2001). Review: Knowledge Management and Knowledge Management Systems: Conceptual Foundations and Research Issues. MIS Quarterly, 25(1), 107-136. http://dx.doi.org/10.2307/3250961

Allison, M., \& Kaye, J. (1997). Strategic Planning for Nonprofit Organizations: A Practical Guide and Workbook. New York: John Wiley \& Sons, Inc.

Argote, L. (2011). Organizational Learning Research: Past, Present and Future. Management Learning, 42(4), 439-446. http://dx.doi.org/10.1177/1350507611408217

Ashton, D. N. (2004). The Impact of Organisational Structure and Practices on Learning in the Workplace. International Journal of Training \& Development, $8(1), \quad 43-53$. http://dx.doi.org/10.1111/j.1360-3736.2004.00195.x

Bapuji, H., \& Crossan, M. (2004). From Questions to Answers: Reviewing Organizational Learning Research. Management Learning, 35(4), 397-417. http://dx.doi.org/10.1177/1350507604048270

Blackler, F., \& McDonald, S. (2000). Power, Mastery and Organizational Learning. Journal of Management Studies, 37(6), 833-851. http://dx.doi.org/10.1111/1467-6486.00206

Brace, I. (2008). Questionnaire Design How to Plan, Structure and Write Survey Material for Effective Market Research. University of Liverpool Catalogue.

Crossan, M. M., Lane, H. W., \& White, R. E. (1999). An Organizational Learning Framework: From Intuition to Institution. Academy Of Management Review, 24(3), 522-537. http://dx.doi.org/10.5465/AMR.1999.2202135

Cyert, R., \& March, J. (1992). A Behavioral Theory of the Firm. Oxford: Blackwell Business.

Droege, S. B., \& Hoobler, J. M. (2003). Employee Turnover and Tacit Knowledge Diffusion: A Network Perspective. Journal of Managerial Issues, 15(1), 50-64.

Drucker, P. F. (1990). Managing the Non-Profit Organization. New York: HarperCollins Publishers.

Ferris, G. R., \& Kacmar, K. M. (1992). Perceptions of Organizational Politics. Journal of Management, 18(1), 93-116. http://dx.doi.org/10.1177/014920639201800107

Fontana, A., \& Frey J. (2003). The Interview: From Structured Questions to Negotiated Texts. In N. Denzin \& Y. Lincoln (Eds.), Collecting and Interpreting Qualitative Materials (2nd ed., pp. 645-672). Thousand Oaks, CA: Sage.

Gill, S. (2010). Developing a Learning Culture in Nonprofit Organizations. Thousand Oaks: SAGE Publications.

Holste, J., \& Fields, D. (2010). Trust and Tacit Knowledge Sharing and Use. Journal of Knowledge Management, 14(1), 128-140. http://dx.doi.org/10.1108/13673271011015615

Janz, B. D., \& Prasarnphanich, P. (2003). Understanding the Antecedents of Effective Knowledge Management: The Importance of a Knowledge-Centered Culture. Decision Sciences, 34(2), 351. http://dx.doi.org/10.1111/1540-5915.02328

Lawrence, T. B., Mauws, M. K., Dyck, B., \& Kleysen, R. F. (2005). The Politics of Organizational Learning: Integrating Power into the 41 Framework. Academy of Management Review, 30(1), 180-191. http://dx.doi.org/10.5465/AMR.2005.15281451

Li, Y., Zhang, C., Liu, Y., \& Li, M. (2010). Organizational Learning, Internal Control Mechanisms, and Indigenous Innovation: The Evidence from China. Ieee Transactions on Engineering Management, 57(1), 63-77. http://dx.doi.org/10.1109/TEM.2009.2028321

Liao, L. (2006). A Learning Organization Perspective on Knowledge-Sharing Behavior and Firm Innovation. Human Systems Management, 25(4), 227-236.

López, S.P., Peón, J.M.M., \& Ordás, C.J.V. (2004). Managing Knowledge: The Link between Culture and Organizational Learning. Journal of Knowledge Management, 8(6), 93-104. http://dx.doi.org/10.1108/13673270410567657

López, S.P., Peón, J.M.M., \& Ordás, C.J.V. (2005). Organizational Learning as a Determining Factor in Business Performance. The Learning Organization, 12(3), 227-245. 
López, S.P., Peón, J.M.M., \& Ordás, C.J.V. (2006). Human Resource Management as a Determining Factor in Organizational Learning. Management Learning, 37(2), 215-239. http://dx.doi.org/10.1177/1350507606063443

Marsick, V. J., \& Watkins, K. E. (2003). Demonstrating the Value of an Organization's Learning Culture: The Dimensions of the Learning Organization Questionnaire. Advances in Developing Human Resources, 5(2), 132-151. http://dx.doi.org/10.1177/1523422303005002002

Martínez-León, I., \& Martínez-García, J. A. (2011). The Influence of Organizational Structure on Organizational Learning. International Journal of Manpower, 32(5/6), 537-566. http://dx.doi.org/10.1108/01437721111158198

Molina-Azorin, J. (2010). The Use and Added Value of Mixed Methods in Management Research. Journal of Mixed Methods Research, 5(1), 7-24. http://dx.doi.org/10.1177/1558689810384490

Nonaka, I., Toyama, R., \& Byosiere, P. (2003). A Theory of Organizational Knowledge Creation: Understanding the Dynamic Process of creating Knowledge. In Dierkes, M., Berthoin-Antal, A., Child, J., \& Nonaka, I. (Eds.), Handbook of Organisational Learning and Knowledge (pp. 491-517). Oxford: Oxford University Press.

Nonaka, I., \& Von Krogh (2009). Tacit Knowledge and Knowledge Conversion: Controversy and Advancement in Organizational Knowledge Creation Theory. Organization Science, 20(3), 635-652. http://dx.doi.org/10.1287/orsc.1080.0412

Pawlowsky, P. (2003). The Treatment of Organizational Learning in Management Science. In Dierkes, M. et al. (Eds.), Handbook of Organisational Learning and Knowledge. Business Source Premier.

Prugsamatz, R. (2010). Factors That Influence Organization Learning Sustainability in Non-Profit Organizations. Learning Organization, 17(3), 243-267.

Rashman, L., Withers, E., \& Hartley, J. (2009). Organizational Learning and Knowledge in Public Service Organizations: A Systematic Review of the Literature. International Journal of Management Reviews, 11(4), 463-494. http://dx.doi.org/10.1111/j.1468-2370.2009.00257.x

Rebelo, T., \& Gomes, A. (2011). Conditioning Factors of an Organizational Learning Culture. Journal of Workplace Learning, 23(3), 173-194. http://dx.doi.org/10.1108/13665621111117215

Roome, N., \& Wijen, F. (2006). Stakeholder Power and Organizational Learning in Corporate Environmental Management. Organization Studies, 27(2), 235-263. http://dx.doi.org/10.1177/0170840605057669

Schilling, J., \& Kluge, A. (2009). Barriers to Organizational Learning: An Integration of Theory and Research. International Journal of Management Reviews, $11(3), \quad 337-360$. http://dx.doi.org/10.1111/j.1468-2370.2008.00242.x

Senge, P. (2006). The Fifth Discipline - The Art and Practice of the Learning Organization, Revised Edition. New York: Currency, Doubleday.

Suppiah, V., \& Sandhu, M. (2011). Organisational Culture's Influence on Tacit Knowledge-Sharing Behaviour. Journal of Knowledge Management, 15(3), 462-477. http://dx.doi.org/10.1108/13673271111137439

SurveyGizmo. (2012). SurveyGizmo. Software Version: 3.37.6.

Townley, B. (1993). Foucault, Power/Knowledge and its Relevance for Human Resource Management. Academy of Management Review, 18(3), 518-545. http://dx.doi.org/10.5465/AMR.1993.9309035149

Vigoda, E. (2000). Organizational Politics, Job Attitudes, and Work Outcomes: Exploration and Implications for the Public Sector. Journal of Vocational Behavior, 57(3), 326-347. http://dx.doi.org/10.1006/jvbe.1999.1742

Von Krogh, G., Ishijo, K., \& Nonaka, I. (2000). Enabling Knowledge Creation: How to Unlock the Mystery of Tacit Knowledge and Release the Power of Innovation (1st ed.). New York: Oxford University Press. http://dx.doi.org/10.1093/acprof:oso/9780195126167.001.0001

Von Krogh, G., Nonaka, I., \& Rechsteiner, L. (2012). Leadership in Organizational Knowledge Creation: A Review and Framework. Journal of Management Studies, 49(1), 240-277. http://dx.doi.org/10.1111/j.1467-6486.2010.00978.x

White, B. (2000). Study Skills for Business and Management Students. Cengage Learning EMEA, Hampshire, UK.

Wielenga-Meijer, E., Taris, T., Wigboldus, D., \& Kompier, M. (2011). Costs and Benefits of Autonomy when Learning a Task: An Experimental Approach. The Journal of Social Psychology, 151(3), 292-313. http://dx.doi.org/10.1080/00224545.2010.481688

Zell, D. (2001). Overcoming Barriers to Work Innovations: Lessons Learned at Hewlett-Packard. Organizational Dynamics, 30(1), 77-86. http://dx.doi.org/10.1016/S0090-2616(01)00042-0 